\title{
Supply Chain Pricing Decisions under Corporation Social Responsibility
}

\author{
Meixiang Wu, Chengdong Shi, Qiang Sun
}

School of Management, Shandong University of Technology, Zibo, 255000, China

\begin{abstract}
The multiple push from the government, the public and non-governmental organizations has increased CSR awareness and makes CSR behavior of cooperators an issue. Considering the impact of sales efforts on demand, making the supply chain which dominated and undertakes the sales effort by retailers as the research object, This paper compares three models of the node enterprise pricing decisions in three CSR commitment models, studies the impact of CSR participation and sales efforts on member profits and social welfare. The study found that the three models can improve social welfare, sales efforts can reduce prices and increase sales; There is a big profit gap and different pricing strategies between $M$ mode and $R$ mode; The social welfare is the large st under MR model, However, there is a threshold for CSR engagement in this model, the supply chain profit shows a downward trend beyond the threshold.
\end{abstract}

Keywords-Corporate social responsibility (CRS), supply chain, pricing decisions, Stackelberg game, sales efforts.

\section{INTRODUCTION}

Corporate social responsibility (CSR) refers to the responsibility of enterprises to shareholders and stakeholders such as employees, consumers, environment and communities. Corporate CSR behavior has an obvious effect on forward and reverse supply chain, For example, it affects the overall performance of third-party recycling CLSC network (Li et al 2017), reverse logistics recovery mode (Wen and Dong 2016), supplier quality information (Fan et al 2017), product demand (Li et al 2017) and so on. Corporate social responsibility is becoming a new competition parameter of supply chain (Wu 2013). Therefore, it is of great practical significance to study the decision-making evolution rules of supply chain members under CSR behavior and reasonable planning social responsibilities of all parties.

Supply chain decision-making under CSR can be divided into four aspects: Firstly, Single supply chain pricing decision. Panda (2017) studied the impact of CSR on retailer recycling and manufacturer recycling CLSC decisions respectively. Liu and Zhou (2016) studied the supply chain optimal decision of each me mber participating in CSR activities under asymmetric market demand information. $\mathrm{Li}$ et al (2017) took the two-level manufacturing chain dominated by component suppliers as the research object, and analyzed the impact of equity concerns supply chain decisions under the circumstance that both parties' social responsibility input influences the demand. Zheng et al (2008) studied the influence of supply chain members' CSR input behavior in closed-loop supply chain.

Secondly, Competitive decision in supply chain. Song et al (2016) studied the pricing decision problem when $1 M+1 R$ assumed CSR in $1 M+2 R$ supply chain. Liang et al (2013) constructed two competitive supply chain games considering CSR behavior, and proposed that supply chain with CSR differentiation strategy is more competitive.

Thirdly, Supply chain coordination under CSR. Hsueh (2014) proposed an integrated corporate social responsibility and coordination mechanism when manufacturers invest in CSR and charge wholesale prices to retailers. Wu (2016) built three game models of cost-benefit sharing mechanisms according to different subjects of social responsibility, and compared pricing decisions of members under different sharing mechanisms. 
Fourthly, CSR integrated governance. Gong et al (2012) constructed a supply chain social responsibility model under consumer preference, and analyzed the internal motivation and government incentive mode of the supply chain to fulfill social responsibility. Li and Huang (2016) proposed an integrated governance model of supply chain social responsibility from the perspective of value creation incentive of supply chain integration. This article focuses only on the first aspect.

At present, most supply chain pricing decisions under CSR are based on manufacturers' leading supply chain, and the considerations focused on equity concerns, Supply chain competition, information asymmetry, consumer prefe rence, sales effort, CSR cost, etc. The innovation of this paper are as follows: Firstly, The research object is the retailer dominated supply chain; Secondly, The demand is influenced by sales efforts and corporate social responsibility are both considered in the supply chain decision-making model.

To sum up, this paper aims to exp lore the following issues: Firstly, Research on three CSR models: The influence of the two parameters (CSR participation, sales effort) on system pricing, sales volume, member profit and social welfare; Secondly, Comparis on of different CSR models: member decision-making, member profits and social welfare; Thirdly, CSR model selection from the perspective of each member. In this paper, the evolution law of supply chain under CSR behavior is discussed to provide decision-making support for enterprises to select and formulate suitable CSR undertaking mode.

\section{PROBLEM DESCRIPTION AND HYPOTHESIS}

This paper takes the retailer-led supply chain as the research object. The retailer and the manufacturer both make rational decisions, have some CSR awareness, and have complete information about each other. The demand

$$
p=m+w, q=a-\beta p+\gamma h, \quad q>0, w>0, m>0, p>0, h>0
$$

is affected by the price and the retailer's sales efforts. represent market demand, wholesale price, retailer's profit per unit product, selling price, and retailer's sales effort, respectively.

Assumed that the seller's cost of selling effort is $I=0.5 \delta h^{2}$, in which $\eta>0$ represents the cost coefficient of sales effort; Manufacturers and retailers may have some sense of social responsibility, and the manufacturer's and the retailer's degree of social responsibility are $0 \leq r_{m}, r_{r} \leq 1$ respectively. It is assumed that consumer surplus is ${ }_{C S}=\int_{p_{\min }}^{p_{\max }} q d p=\frac{[a-\beta p+\gamma h]^{2}}{2 \beta^{2}}$, $\pi_{i}$ and $V_{i}^{j}$ represent the net profit and profit of member $\mathrm{i}$ under certain social responsibility, in which $i=m, r, s c$ represent manufacturer, retailer and supply chain respectively and ${ }_{j=M, R, S C}$ represent three modes of social responsibility: manufacturer, retailer and both parties. For simplicity, take $r_{m}=r_{r}=r$. In order to ensure that the profit function of each me mber enterprise is concave and relevant expressions are feasible, assumed that $0<\gamma<\sqrt{(2-3 r / 2) \beta \delta}$.

\section{MODEL CONSTRUCTION AND ANALYSIS OF EQUILIB RIUM RESULTS}

3.1 The case of $\mathrm{R}$ taking on CSR ( $\mathrm{R}$ model)

According to the definition of social welfare in economics: social welfare is equal to the sum of retailer surplus (retailer profit) and consumer surplus,

Consumer surplus is the difference between the actual market price and the maximum price of which consumers are willing to pay for a product. In this case, the profit function of manufacturer and retailer is respectively:

$$
\begin{aligned}
& V_{r}^{R}(m, h)=\pi_{r}^{R}+C S_{r}^{R}=m w[a-\beta(w+m)+\gamma h]-0.5 \delta \mathrm{h}^{2}+\frac{[a-\beta(w+m)+\gamma h]^{2}}{2 \beta} \\
& \pi_{m}^{R}(w)=w[a-\beta(w+m)+\gamma h]
\end{aligned}
$$

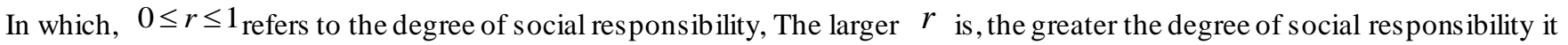
takes.

In $\mathrm{R}$ mode, the solution result is shown in equation (2) : 


$$
\begin{aligned}
& m^{R}=\frac{\delta a(2-r)}{4 \beta \delta-\beta \delta r-\gamma^{2}}, w^{R}=\frac{\delta a}{4 \beta \delta-\beta \delta r-\gamma^{2}}, p^{R}=\frac{\delta a(3-r)}{4 \beta \delta-\beta \delta r-\gamma^{2}}, q^{R}=\frac{\beta \delta a}{4 \beta \delta-\beta \delta r-\gamma^{2}} \mathrm{~h}^{R}=\frac{\gamma a}{4 \beta \delta-\beta \delta r-\gamma^{2}} \\
& \pi_{r}^{R}=\frac{a^{2} \delta\left[2(2-r) \beta \delta-\gamma^{2}\right]}{2\left[(4-r) \beta \delta-\gamma^{2}\right]^{2}}, \pi_{m}^{R}=\frac{\beta \delta^{2} a^{2}}{\left(4 \beta \delta-\beta \delta r-\gamma^{2}\right)^{2}}, \pi_{s c}^{R}=\frac{a^{2} \delta\left[(6-2 r) \beta \delta-\gamma^{2}\right]}{2\left(4 \beta \delta-\beta \delta r-\gamma^{2}\right)^{2}}, V_{r}^{R}=\frac{\left[\beta \delta(5-2 r)-\gamma^{2}\right] a^{2} \delta}{2\left(4 \beta \delta-\beta \delta r-\gamma^{2}\right)^{2}}, V_{s c}^{R}=\frac{\left[\beta \delta(7-2 r)-\gamma^{2}\right] a^{2} \delta}{2\left(4 \beta \delta-\beta \delta r-\gamma^{2}\right)^{2}}
\end{aligned}
$$

Theorem 1: $w^{R}, h^{R}, q^{R}$ is positively related to $\mathrm{r}, m^{R}, p^{R}$ is negatively correlated with $\mathrm{r}$.

Proof:

$$
\begin{aligned}
& \frac{\partial w^{R}}{\partial r}=\frac{a \beta \delta^{2}}{\left[4 \beta \delta-\beta \delta r-\gamma^{2}\right]^{2}}>0, \frac{\partial q^{R}}{\partial r}=\frac{a \beta^{2} \delta^{2}}{\left[4 \beta \delta-\beta \delta r-\gamma^{2}\right]^{2}}>0, \frac{\partial h^{R}}{\partial r}=\frac{a \beta \delta \gamma}{\left[4 \beta \delta-\beta \delta r-\gamma^{2}\right]^{2}}>0 \\
& \frac{\partial m^{R}}{\partial r}=\frac{\left(-2 \beta \delta+\gamma^{2}\right) \delta a}{\left[4 \beta \delta-\beta \delta r-\gamma^{2}\right]^{2}}<0, \frac{\partial p^{R}}{\partial r}=\frac{\left(-\beta \delta+\gamma^{2}\right) \delta a}{\left[4 \beta \delta-\beta \delta r-\gamma^{2}\right]^{2}}<0
\end{aligned}
$$

Equation 3 shows that: Under R's social responsibility, R stimulates consumer demand and expands product demand by lowering selling price and improving sales efforts. In R mode, the manufacturers is in a subordinate position, meanwhile it is not constrained by the sense of social responsibility. Therefore, when the market demand expands, the manufacturer will increase the wholesale price without restriction in order to maximize its own profit. The implementation of a series of measures, such as raising the wholesale price, reducing the cost of sales efforts and lowering the selling price, will great ly reduce the unit product profit of retailers.

Theorem 2: $\pi_{m}^{R}, \pi_{s c}^{R}, V_{m}^{R}, V_{s c}^{R}$ is positively related to $\mathrm{r}, \pi_{r}^{R}$ is negatively correlated with $\mathrm{r}$;

Proof:

$$
\begin{aligned}
& \frac{\partial \pi_{r}^{R}}{\partial r}=\frac{-2 r \beta^{2} \delta^{3} a^{2}}{2\left[(4-r) \beta \delta-\gamma^{2}\right]^{3}}<0, \frac{\partial \pi_{m}^{R}}{\partial r}=\frac{2 \beta^{2} \delta^{3} a^{2}\left(4 \beta \delta-r \beta \delta-\gamma^{2}\right)}{\left(4 \beta \delta-\beta \delta r-\gamma^{2}\right)^{4}}>0, \frac{\partial \pi_{s c}^{R}}{\partial r}=\frac{(4-2 r) a^{2} \delta^{2} \beta^{2} \delta^{2}}{2\left(4 \beta \delta-\beta \delta r-\gamma^{2}\right)^{3}}>0 \\
& \frac{\partial V_{r}^{R}}{\partial r}=\frac{a^{2} \beta^{2} \delta^{3}(2-r)}{2\left(4 \beta \delta-\beta \delta r-\gamma^{2}\right)^{3}}>0, \frac{\partial V_{s c}^{R}}{\partial r}=\frac{(3-r) a^{2} \delta^{3} \beta^{3}}{\left(4 \beta \delta-\beta \delta r-\gamma^{2}\right)^{3}}>0
\end{aligned}
$$

Equation 4 shows that: With the increasing awareness of social responsibility of leading retailers, the price reduction and sales efforts of retailers not only provide social welfare, but also improve the overall profit of all members of the system. Altho ugh the retailer sacrifices some of its own pure profits, all members benefit from it, which is in line with the leading party with a sense of social responsibility to pay attention to its stakeholders. Furthermore, the stronger the retailer's awareness of social responsibility, the more obvious the improvement of the stakeholders' and the system's overall profit.

3.2 The case of $M$ taking on CSR ( $\mathrm{M}$ model)

In this case, the profit function of manufacturer and retailer is respectively:

$$
\begin{aligned}
& V_{m}^{M}(w)=\pi_{m}+C S_{m}=w[a-\beta(w+m)+\gamma h]+\frac{[a-\beta(w+m)+\gamma h]^{2}}{2 \beta} \\
& \pi_{r}^{M}(m, h)=m w[a-\beta(w+m)+\gamma h]-0.5 \delta \mathrm{h}^{2}
\end{aligned}
$$

The game process is as follows: Firstly, R determines the degree of sales effort, then $\mathrm{M}$ determines the wholesale price, and the solution is:

$$
\begin{aligned}
& m^{M}=\frac{(2-r) \delta a}{2(2-r) \beta \delta-\gamma^{2}}, w^{M}=\frac{(1-r) \delta a}{2(2-r) \beta \delta-\gamma^{2}}, p^{M}=\frac{(3-2 r) \delta a}{2(2-r) \beta \delta-\gamma^{2}}, h^{M}=\frac{a \gamma}{2(2-r) \beta \delta-\gamma^{2}}, q^{M}=\frac{\beta \delta a}{2(2-r) \beta \delta-\gamma^{2}} \\
& \pi_{r}^{M}=\frac{a^{2} \delta}{2\left[2(2-r) \beta \delta-\gamma^{2}\right]}, \pi_{m}^{M}=\frac{(1-r) \beta \delta^{2} a^{2}}{\left[(4-2 r) \beta \delta-\gamma^{2}\right]^{2}}, \pi_{s c}^{M}=\frac{\left[(5-3 r) \beta \delta-\gamma^{2}\right] a^{2} \delta}{\left[2(2-r) \beta \delta-\gamma^{2}\right]^{2}}, V_{m}^{M}=\frac{(2-r) \beta \delta^{2} a^{2}}{2\left[2(2-r) \beta \delta-\gamma^{2}\right]^{2}},,_{s c}^{M}=\frac{\delta a^{2}\left[3(2-r) \beta \delta-\gamma^{2}\right]}{2\left[2(2-r) \beta \delta-\gamma^{2}\right]^{2}}
\end{aligned}
$$

Theorem $3: m^{M}, h^{M}, q^{M}$ is positively related to $\mathrm{r}, w^{M}, \mathrm{p}^{M}$ is negatively correlated with $\mathrm{r}$;

Proof:

$$
\begin{aligned}
& \frac{\partial m^{M}}{\partial r}=\frac{\delta a \gamma^{2}}{\left[2(2-r) \beta \delta-\gamma^{2}\right]^{2}}>0, \frac{\partial w^{M}}{\partial r}=\frac{\left(-2 \beta \delta+\gamma^{2}\right) \delta a}{\left[2(2-r) \beta \delta-\gamma^{2}\right]^{2}}<0, \frac{\partial h^{M}}{\partial r}=\frac{2 a \gamma \beta \delta}{\left[2(2-r) \beta \delta-\gamma^{2}\right]^{2}}>0 \\
& \frac{\partial q^{M}}{\partial r}=\frac{2 a \gamma \beta \delta}{\left[2(2-r) \beta \delta-\gamma^{2}\right]^{2}}>0, \frac{\partial p^{M}}{\partial r}=\frac{\left(-\beta \delta+\gamma^{2}\right) \delta a}{2\left[(2-r) \beta \delta-\gamma^{2}\right]^{2}}<0
\end{aligned}
$$

Equation 7 shows that: Under the social responsibility of M, manufacturers will lower the wholesale price and retailers will increase their sales efforts, so as to increase the sales volume of supply chain products. For dominant retailers, without the cons traint of social res ponsibility, $\mathrm{R}$ will not reduce the profit per unit product, but increase the net profit per unit prod uct due to 
the increase of product demand. In order to stimulate manufacturers' enthusiasm to assume social responsibilities, retailers' $\mathrm{n}$ et profit per unit product will not exceed the limit, that is, the result is a lower price.

Theorem4 : $\pi_{r}^{M}, \pi_{s c}^{M}, V_{m}^{M}, V_{s c}^{M}$ is positively related to $\mathrm{r}$. $\pi_{m}^{M}$ is positively related to $\mathrm{r}$ When $\mathrm{r}$ is less than 0.5 , and $\pi_{m}^{M}$ is negatively correlated with $\mathrm{r}$ when $\mathrm{r}$ is greater than 0.5 .

Proof:

$$
\begin{aligned}
& \frac{\partial \pi_{r}^{M}}{\partial r}=\frac{4 a^{2} \delta^{2}}{2\left[2(2-r) \beta \delta-\gamma^{2}\right]^{2}}>0, \frac{\partial \pi_{m}^{M}}{\partial r}=\frac{\beta \delta^{2} a^{2}\left(-2 r \beta \delta+\gamma^{2}\right)}{\left[(4-2 r) \beta \delta-\gamma^{2}\right]^{3}}<0, \frac{\partial \pi_{s c}^{M}}{\partial r}=\frac{\left[2(4-3 r) \beta \delta+\gamma^{2}\right] a^{2} \delta^{2} \beta}{\left[2(2-r) \beta \delta-\gamma^{2}\right]^{3}}>0 \\
& \frac{\partial V_{m}^{M}}{\partial r}=\frac{\left[(4-2 r) \beta \delta+\gamma^{2}\right] a^{2} \delta^{2} \beta}{2\left[(4-2 r) \beta \delta-\gamma^{2}\right]^{3}}>0, \frac{\partial V_{s c}^{M}}{\partial r}=\frac{\left[6(2-r) \beta \delta+\gamma^{2}\right] a^{2} \delta^{2} \beta}{2\left[2(2-r) \beta \delta-\gamma^{2}\right]^{3}}>0
\end{aligned}
$$

Equation 8 shows that: With the increasing social responsibility of manufacturers, the sales efforts of retailers can improve social welfare, retailers' profits and the overall profit of the supply chain. However, for the manufacturer itself, when the degree of social responsibility is small, it is beneficial to its net profit. However, when the coefficient of social responsibility excee ds 0.5 , some of its profit will suffer, which will greatly reduce the manufacturer's enthusiasm to as sume social responsibility.

3.3 The case of MR taking on CSR (MR model)

Under shared social responsibility and centralized pricing:

$$
V_{s c}^{M R}(p, h)=p_{s c}+C S_{c s}=p[a-b p+g h]-0.5 d h^{2}+\frac{[a-b p+g h]^{2}}{2 b}
$$

Proof:

$$
p^{M R}=\frac{\delta \mathrm{a}(1-\mathrm{r})}{\beta \delta(2-r)-\gamma^{2}}, h^{M R}=\frac{a \gamma}{\beta \delta(2-r)-\gamma^{2}}, \mathrm{q}^{M R}=\frac{\beta \delta \mathrm{a}}{\beta \delta(2-r)-\gamma^{2}}, \pi_{s c}^{M R}=\frac{\beta \delta^{2} \mathrm{a}^{2}(1-\mathrm{r})}{\left[\beta \delta(2-r)-\gamma^{2}\right]^{2}}, V_{s c}^{M R}=\frac{\beta \delta^{2} \mathrm{a}^{2}(3-2 \mathrm{r})}{2\left[\beta \delta(2-r)-\gamma^{2}\right]^{2}}
$$

Theorem5: $h^{M R}, q^{M R}$ is positively related to $\mathrm{r} . \quad p^{M R}$ is negatively correlated with $\mathrm{r}$.

Proof:

$$
\frac{\partial p^{M R}}{\partial r}=\frac{\delta \mathrm{a}\left(-\beta \delta+\gamma^{2}\right)}{\left[\beta \delta(2-r)-\gamma^{2}\right]^{2}}<0, \frac{\partial h^{M R}}{\partial r}=\frac{a \gamma \beta \delta}{\left[\beta \delta(2-r)-\gamma^{2}\right]^{2}}>0, \frac{\partial q^{M R}}{\partial r}=\frac{a \beta^{2} \delta^{2}}{\left[\beta \delta(2-r)-\gamma^{2}\right]^{2}}>0
$$

Theorem 5 shows that: In the MR model, the retailer will reduce the profit of per unit product and increase the level of sales efforts, and the manufacturer will reduce the wholesale price. That is, Concessions from both will be greatly reduced and the sales volume of the product will be increased.

Theorem6 : $\pi_{s c}^{M R}$ is negatively correlated with $\mathrm{r} . \quad V_{s c}^{M R}$ is positively related to $\mathrm{r}$.

Proof:

$$
\frac{\partial \pi_{s c}^{M R}}{\partial r}=\frac{\beta \delta^{2} \mathrm{a}^{2}\left[(-r) \beta \delta+\gamma^{2}\right]}{\left[\beta \delta(2-r)-\gamma^{2}\right]^{3}}<0, \frac{\partial V_{s c}^{M R}}{\partial r}=\frac{\beta \delta^{2} \mathrm{a}^{2}\left[\beta \delta(-1+2 r)+2 \gamma^{2}\right]}{2\left[\beta \delta(2-r)-\gamma^{2}\right]^{3}}>0
$$

In the MR model, When the social welfare is the largest and the overall profit of the supply chain is the best, the CSR threshold is $2 / 3$. With the enhancement of social responsibility, CSR behaviors of members will sacrifice part of their own interests to maximize social welfare.

3.4 pattern comparison and analysis

Theorem 7: $h^{R}<h^{M}<h^{M R}, q^{R}<q^{M}<q^{M R}, p^{R}>p^{M}>p^{M R}, m^{R}<m^{M}, w^{R}>\mathrm{w}^{M}$

Theorem 7 shows that: Under the three modes, In the MR model, the selling price is the lowest, the sales effort is the strongest and the product sales volume is the largest. This is because manufacturers and retailers at the same time make profits to consumers in the MR model,, that is, M reduces the wholesale price and R reduces the profit per unit product, which makes the selling price of products drop sharply and the sales volume rise rapidly. 
Theorem 8: $\pi_{r}^{R}<\pi_{r}^{M}, \pi_{m}^{R}>\pi_{m}^{M}, \pi_{s c}^{R}>\pi_{s c}^{M}, V_{s c}^{R}>V_{s c}^{M}$

Theorem 8 shows that: Comparing R model with $\mathrm{M}$ model, When $\mathrm{M}$ assumes social responsibility, R has higher profit, system has higher profit and greater social welfare, but $\mathrm{M}$ has lower profit.

\section{SIMULATION ANALYSIS}

Assuming $q=500-5 p+2 e, \delta=3$, the simulation results in the three models are shown in the table:

Table 1 Comparison of pricing decision variables in three modes

\begin{tabular}{llllllllllllll}
\hline $\mathrm{r}$ & $\mathrm{wM}$ & $\mathrm{wR}$ & $\mathrm{mM}$ & $\mathrm{mR}$ & $\mathrm{pM}$ & $\mathrm{pR}$ & $\mathrm{pMR}$ & $\mathrm{hM}$ & $\mathrm{hR}$ & $\mathrm{hMR}$ & $\mathrm{qM}$ & $\mathrm{qR}$ & $\mathrm{qMR}$ \\
\hline 0.05 & 26.15 & 27.15 & 53.67 & 52.94 & 81.19 & 80.09 & 56.44 & 18.35 & 18.10 & 39.60 & 137.61 & 135.75 & 297.03 \\
0.1 & 25.47 & 27.52 & 53.77 & 52.29 & 82.08 & 79.82 & 55.10 & 18.87 & 18.35 & 40.82 & 141.51 & 137.61 & 306.12 \\
0.15 & 24.76 & 27.91 & 53.88 & 51.63 & 83.01 & 79.53 & 53.68 & 19.42 & 18.60 & 42.11 & 145.63 & 139.53 & 315.79 \\
0.3 & 22.34 & 29.13 & 54.26 & 49.51 & 86.17 & 78.64 & 48.84 & 21.28 & 19.42 & 46.51 & 159.57 & 145.63 & 348.84 \\
0.5 & 18.29 & 30.93 & 54.88 & 46.39 & 91.46 & 77.32 & 40.54 & 24.39 & 20.62 & 54.05 & 182.93 & 154.64 & 405.41 \\
0.7 & 12.86 & 32.97 & 55.71 & 42.86 & 98.57 & 75.82 & 29.03 & 28.57 & 21.98 & 64.52 & 214.29 & 164.84 & 483.87 \\
0.85 & 5.17 & 35.29 & 56.90 & 38.82 & 108.6 & 74.12 & 12.00 & 34.48 & 23.53 & 80.00 & 258.62 & 176.47 & 600.00 \\
\hline
\end{tabular}

It can be seen from Table 1 that:

(1) the common ground of the three models is that with the increase of CSR degree of members, the selling price of products decreases, R's sales efforts increase, and product sales volume increases greatly. In MR mode, the selling price is the lowest, $\mathrm{R}$ has the strongest sales effort and the sales volume is the largest.

(2) Through longitudinal comparison, it can be seen that in the R model, with the stronger CSR participation, the higher wholesale price of the manufacturer, the lower unit product profit and selling price of the retailer, and the higher sales effort. The combination of above is the increase of sales volume. Under M mode, with the enhancement of CSR degree, wholesale price decreases, sales efforts and unit product profits increase, selling price decreases and sales volume increases.

From the perspective of horizontal comparison, manufacturer's wholesale price in mode $R$ is higher than that in mode $\mathrm{M}$, while retailer's unit product profit, selling price, promotion effort and sales volume in mode $\mathrm{M}$ are all higher than that in mode $\mathrm{R}$.

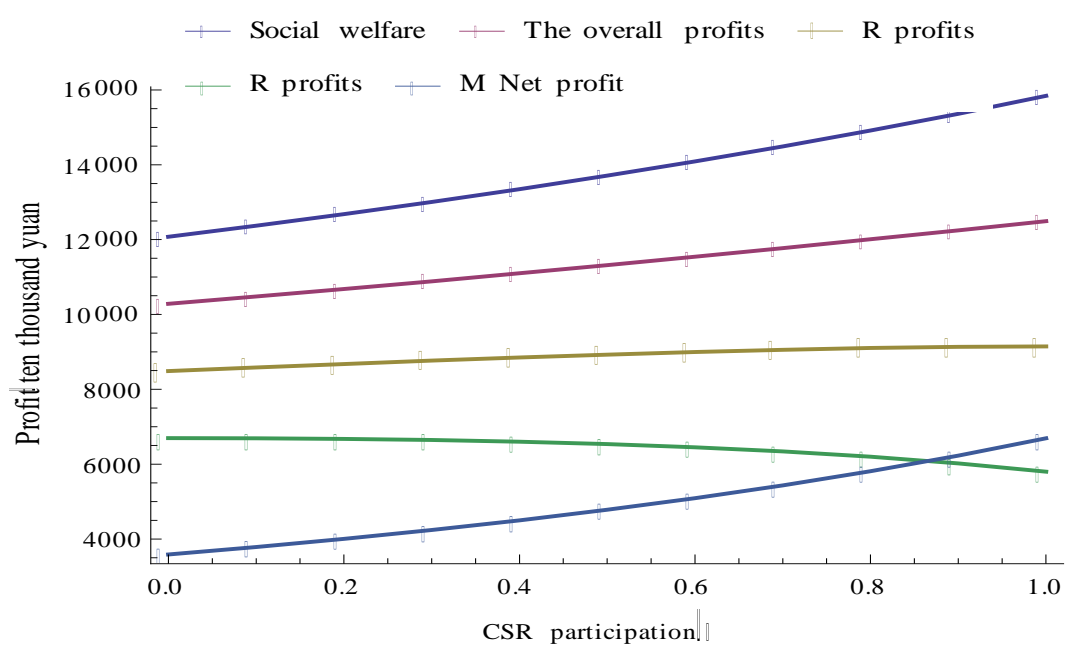

Fig.1: Member profit and social welfare under $R$ mode 


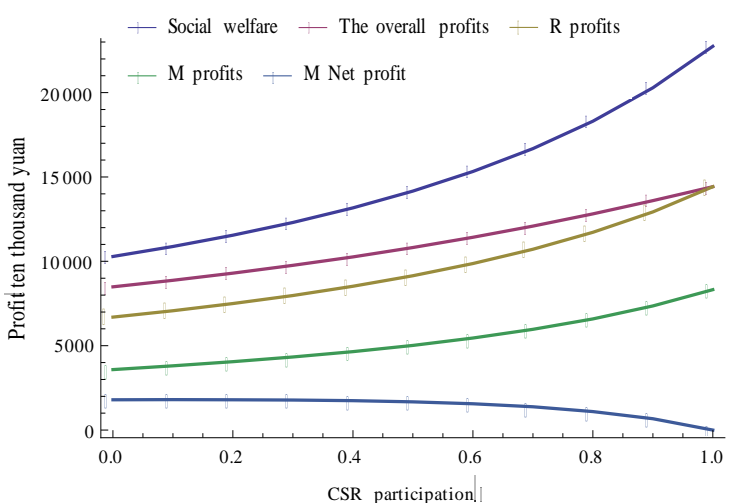

Fig.2: Member profit and social welfare under $M$ mode

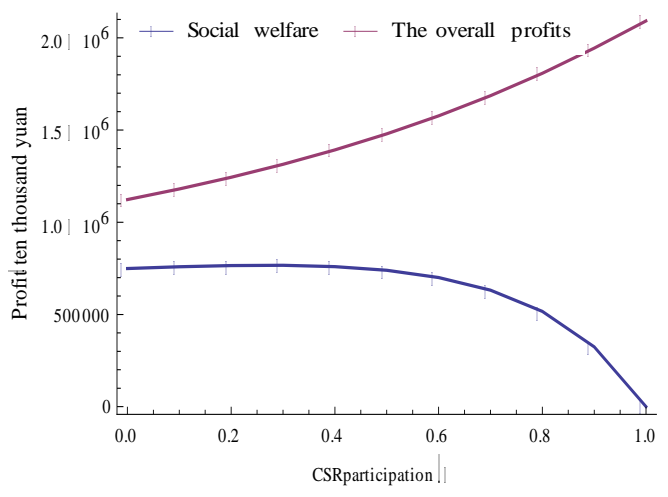

Fig.3: profit and social welfare of SC under MR model

It can be seen from figure 1-3 that: 1) in the M mode, with the increase of M's participation in CSR, social welfare, retailer profit and system profit all increase, but the profits of manufacturers decline. When the CSR degree of M reaches 1 , the social welfare reaches the extre me value, the supply chain profit equals the retailer profit, and the manufacturer profit equals to zero. In the R model, with the increase of R's participation in CSR, social welfare, manufacturer profit and supply chain all increase, but the profits of retailer decrease. When the retailer's level of responsibility is relatively small, the retailer's profit is higher than the manufacturer's. When CSR exceeds the threshold, retailers' profits are lower than manufacturers'.

3) In the MR model, as MR's involvement in CSR increases, social welfare increases, while supply chain profit decreases. In a word, with the increase of CSR, the social welfare of three modes all increases, $d$ the net profit of the underwriters declines.

This proves theorems $1,3,5,7$.

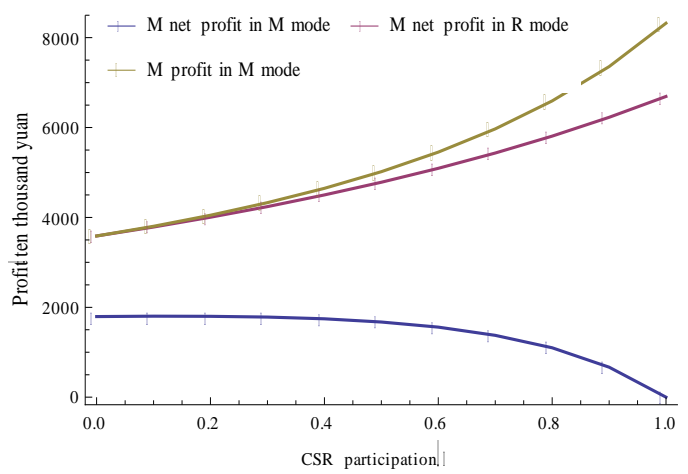

Fig.4: $M$ profit and social welfare under different modes

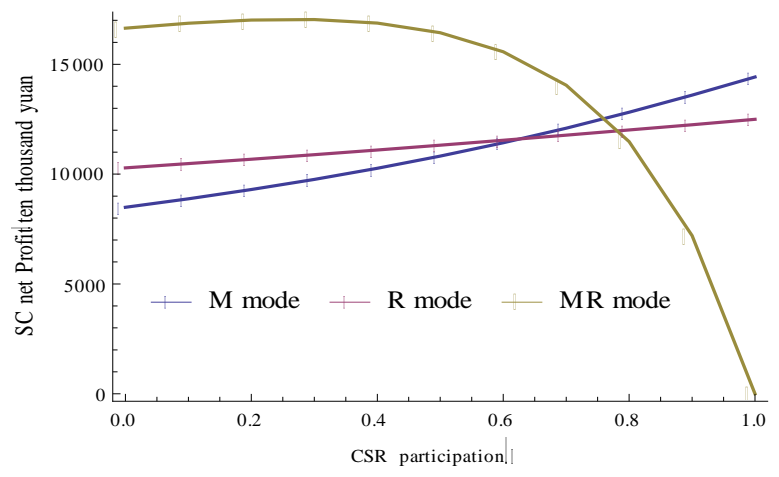

Fig. 6: SC profit under different modes

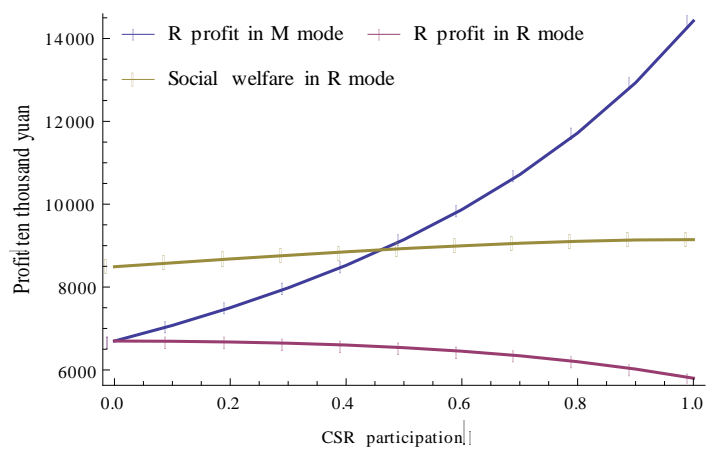

Fig. 5: $R$ profit and social welfare under different modes

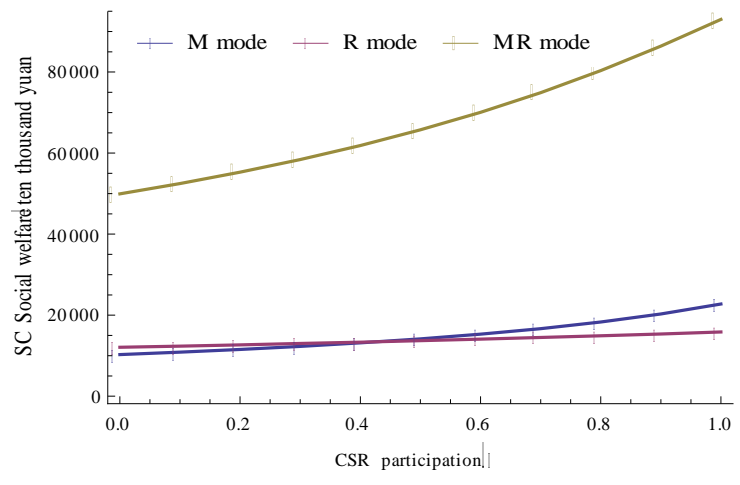

Fig.7: SC social welfare under different mode 
It can be seen from Figure 4-7 that:

(1) the correlation between the profit of each member, social welfare and the degree of social responsibility $r$, which verifies the correctness of conclusions 2,4 and 6;

(2) For M profit, SC profit and social welfare, R mode is better than $\mathrm{M}$ mode, while for $\mathrm{R}$ profit, $\mathrm{M}$ mode is better. These verify the correctness of conclusion 8 ;

(3)From the perspective of supply chain profit, when members participate less in CSR, the MR mode is better, and when the participation degree of social responsibility exceeds the threshold, the $M$ mode is the best, which verifies the correctness of conclusion 8 .

\section{CONCLUSION}

This paper takes the supply chain dominated by retailers and considering sales efforts as the research object, analyzes and studies the pricing decisions of various responsible parties and CSR members under the participation degree of CSR, and discusses the influence of R's sales efforts and CSR behaviors on the supply chain. The following conclusions are drawn:

(1) In all three cases, the retailer's sales efforts reduce prices and increase the sales volume. The more CSR is involved, the influence of retailers' sales efforts on selling price and sales volume is more significant.

(2) In all three cases, the participation of CSR bearers is greater, social welfare is higher, but bear's profits has downward trend.

(3) CSR model and CSR participation level are closely related to supply chain pricing decisions.

This paper only discusses the influence of different CSR models on the profit of supply chain members and social welfare under the $\mathrm{R}$ leading and considering the sales efforts, and considers the production or sales cost, government guidance and other factors, which is the next research direction.

\section{REFERENCES}

[1] Fan, J. C., Ni, D. B., Tang, X. W. (2017) Study on CSR and supply chain product quality selection and coordination contract. Journal of Management, 14: 1374-1383.

[2] Gong, H., Guo, C.X., Li, S. (2012) Internal dynamics of supply chain social responsibility based on consumer preference. Soft
Science, 26: 45-49.

[3] Hsueh, C.F. (2014) Improving corporate social responsibility in a supply chain through a new revenue sharing contract. International Journal of Production Economics, 151:214-222.

[4] Li, B.Y., Liu,Z., Tang, J., Wang, Z. (2017) Research on the decision-making and coordination mechanism of CSR input in supply chain under the concern of equity. Journal of Suzhou University, 5:120-129.

[5] Li, C.B., Yang, Y., He, Y.H. (2017) Hyper network equilibrium model of closed-loop supply chain based on corporate social responsibility. Statistics and Decision-making, 5:172-177.

[6] Li, J.H., Huang, G.Y. (2016) Integrated governance model and mechanism of supply chain social responsibility. Journal of Systems Science, 24: 65-69.

[7] Li, Y. H., Ni, D. B., Tang, X. L. (2017) Game of quality signal transmission of supply chain enterprises based on corporate social responsibility. China Management Science, 25:38-47.

[8] Liang, Y.S., Ni, D.B., Tang, X.W. (2013) Supply chain dual-channel competition model based on corporate social responsibility [J]. China Management Science, 21:453-460.

[9] Liu, G.Q., Zhou, J. (2016) Supply chain decision considering corporate social responsibility under asymmetric information. Journal of Hefei University of Technology, 39: 859-865.

[10] Panda, S., Modak, N.M., Cardenas-Barron, L.E. (2017) Coordinating a socially responsible closed-loop supply chain with product recycling. International Journal of Production Economics, 188:11-21.

[11] Song, J.Z., Huang, Y.F., Gu, J.W. (2016) Research on supply chain equilibrium decision of single manufacturer and two retailers with social responsibility consciousness. Jo urnal of Management, 13: 1571-1578.

[12] Wen, X. Q., Dong, Y. R. (2016) Selection of reverse logistics recycling mode based on corporate social responsibility. Operations Planning and Management, 25: 275-281.

[13] Wu, C.H. (2016) Collaboration and sharing mechanisms in improving corporate social responsibility [J].Central European Journal of Operations Research, 24:681-707.

[14] Wu, D. Y. (2013) Research on CSR management of supply chain enterprises. China Soft Science, 2: 55-63.

[15] Zheng, B. R., Yang, C., Yang,J. (2008) Impact of CSR input on closed-loop supply chain pricing and coordination decision. China Management Science, 26: 64-78. 